\title{
Analysis and modeling of debris flows in Gargano watersheds (Puglia region, Southern Italy)
}

\author{
F. Gentile, T. Bisantino, S. Puglisi \& G. Trisorio Liuzzi \\ Department of Engineering and Management of the Agricultural, \\ Livestock and Forest Systems, University of Bari, Italy
}

\begin{abstract}
In the past, the alluvial fan of Pulsano torrent, located on the southern hillslope of the promontory of Gargano, was exposed to intense debris flows.

In this paper, a methodology of debris flows modeling is applied to the watershed to delineate the hydrogeological risk situations in valley areas. For this purpose, hazard potential and vulnerability conditions of the concerned areas are investigated in order to plan and guide measures aimed at limiting the damages such hazards may cause.
\end{abstract}

Keywords: debris flow, risk assessment, control measures.

\section{Introduction}

The southern hillslope of the Gargano promontory (Puglia Region, Southern Italy) is crossed by several torrents shaped in calcareous formations prone to mechanical erosion caused by heavy rainfall.

In the last century some exceptional events have affected the area between the Monte Sant'Angelo and Manfredonia towns Curci et al. [1]. The debris flow that occurred on 15 July 1972 was the most catastrophic event. It caused fatalities in the town of Manfredonia. Cars were swept away by the flow and deposited along the streets that turned into conveyance channels, and the surrounding agricultural areas were flooded. In view of that, hydraulic management works (check dams, gabions or concrete banks, sills) were built in some watersheds.

This paper describes a methodology to analyse debris flow risk in this area, starting from the estimation of potential debris volumes. This is followed by the debris flow modeling targeted at producing hazard mapping and the land 
vulnerability assessment. This approach is applied in the Pulsano watershed, having typical Mediterranean climatic, morphological and vegetal conditions and where no monitoring is provided.

\section{Materials and methods}

\subsection{Study site}

The study area extends from the Gargano promontory (880 $\mathrm{m}$ a.s.1), where Pulsano torrent originates, down to the alluvial fan developing over the agricultural and industrial area of Manfredonia town. Table 1 reports the main characteristics of the Pulsano watershed.

Table 1: $\quad$ Main characteristics of the Pulsano watershed.

\begin{tabular}{|c|c|c|}
\hline Basin area $\mathrm{A}$ & 15.6 & $\mathrm{~km}^{2}$ \\
\hline Mean altitude & 464 & $\mathrm{~m}$ a.s.l. \\
\hline Maximum altitude & 884 & $\mathrm{~m}$ a.s.l. \\
\hline Minimum altitude & 100 & $\mathrm{~m}$ a.s.l. \\
\hline Main channel slope i & 17.5 & $\%$ \\
\hline Average alluvial cone slope $S_{f}$ & 14.0 & $\%$ \\
\hline Main channel lenght $\mathrm{L}_{\mathrm{c}}$ & 3900 & $\mathrm{~m}$ \\
\hline
\end{tabular}

The Pulsano torrent has a rather complex watershed area with dolines in the top portion and many cross-valleys. Hillslopes are characterized by the presence of dry stone walls that collapse at several points due to increasing state of neglect. This contributes to increase the amount of soil and debris transported downstream also as a result erosion from hillslopes inadequately protected by rare and degraded forests. The stream bed is eroded because of scouring and bank failure with the deposition of small and medium-size boulders.

The parent material is mainly composed of dolomitic limestone (TriassicCretaceous era) compact, whitish, richly organic and fairly permeable because of fissuring and irregular beddings of calcarenite and calcirudite. The debris cone is composed of calcareous fragments and blocks in a silt-clay matrix. The vegetal cover is mainly characterized by natural grazing. Prairies and broad-leaved woods are present at high altitudes, the cone area is cultivated with olive trees and crops and natural areas are located near the torrent.

In the last century some exceptional events affected the area between the Monte Sant'Angelo and Manfredonia towns. During July 15, 1972 and July 29, 1976 events, rainstorms saturated the steep slopes of the watersheds and evolved into debris flows that flooded the agricultural areas and reached the coastal town of Manfredonia in the early hours, fig. 2. Figure 3 reports the hourly and cumulated precipitation of the 15 July 1972 event. 
Monitoring, Simulation, Prevention and Remediation of Dense and Debris Flows 183
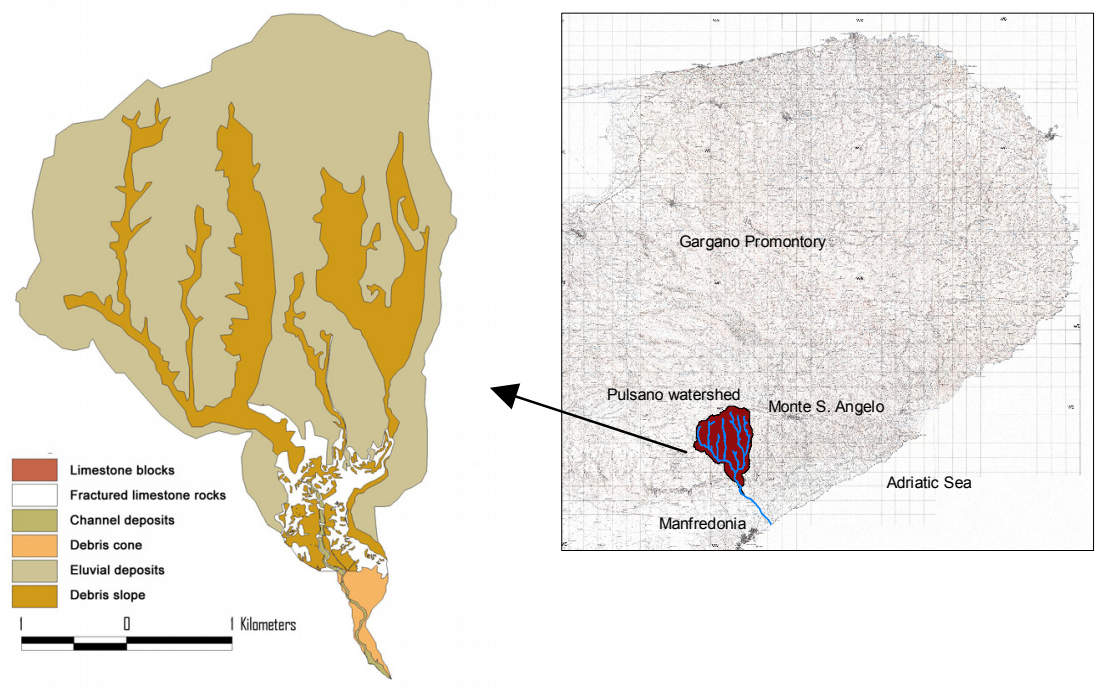

Figure 1: The geolithologic units of the Pulsano watershed.
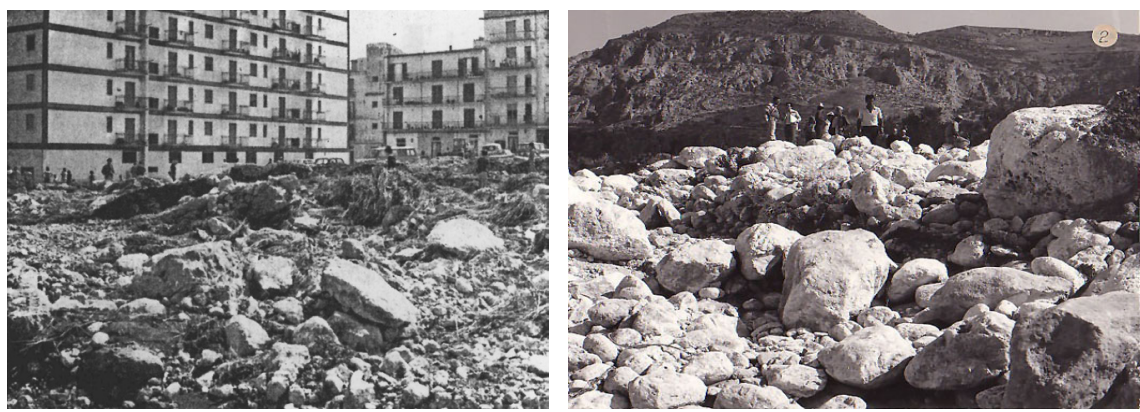

Figure 2: $\quad$ The 15 July 1972 (left) and 29 July 1976 (right) events.

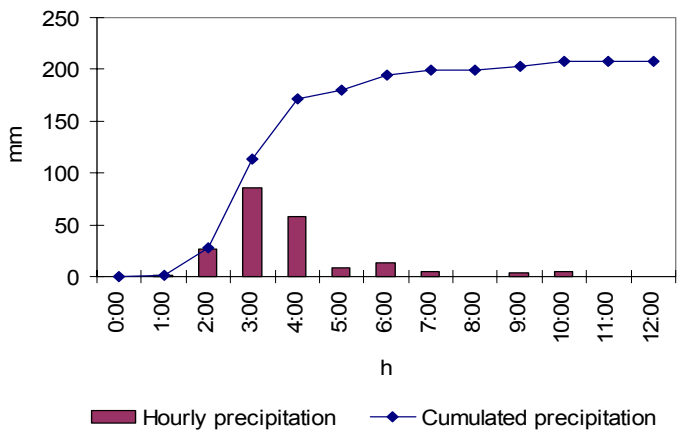

Figure 3: Hourly and cumulated rainfall of the 15 July 1972 event.

WIT Transactions on Ecology and the Environment, Vol 90, (C) 2006 WIT Press

www.witpress.com, ISSN 1743-3541 (on-line) 
After such catastrophic and heavy rainfall events, hydraulic management works were carried out: concrete check dams, gabions to protect banks from erosion processes, metal nets to avoid unsteady rocks rolling down, concrete banks and sills to channel runoff, fig. 4 .
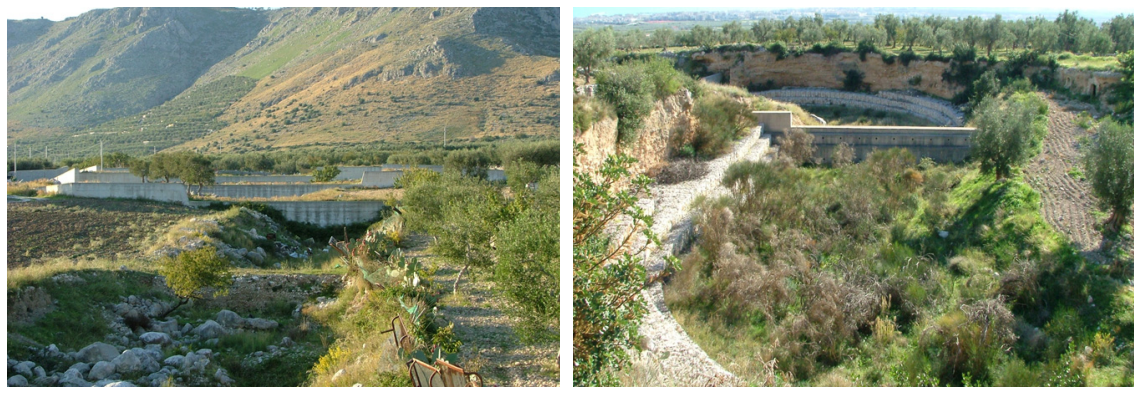

Figure 4: Check dams (left) and gabions (right) along the Pulsano torrent.

\subsection{The debris flow modeling}

This section describes the methodology applied to analyse debris flow phenomena in the Pulsano watershed, starting from the estimation of potential debris volumes, then followed by the two-dimensional simulation over the alluvial fan.

The amount of material detatched from hillslopes during heavy rainstorms was estimated applying a process based model for terrain stability mapping such as SHALSTAB Montgomery and Dietrich [2]. This model, like SINMAP Pack et al [3] and LISA Hammond et al. [4], assumes steady state, saturated flow parallel to the slide surface, while the model developed by Iverson [5] considers transient unsaturated flow Morrissey et al. [6].

The use of a stability model that enable to get hillslope sensitivity to precipitation could provide an appropriate solution to the specific conditions of the watershed, in that it allows to determine the triggering conditions and the pattern of potential shallow slopes instability.

The Montgomery and Dietrich physically based stability model (SHALSTAB) estimates the unstable areas applying the equation:

$$
Q=\frac{T \operatorname{sen} \theta}{a / b}\left[\frac{c}{\rho_{w} g z \cos ^{2} \theta \tan \varphi}+\frac{\rho_{s}}{\rho_{w}}\left(1-\frac{\tan \theta}{\tan \varphi}\right)\right]
$$

in which the drainage area multiplied by the length unit $a / b$, the slope gradient $\theta$, the transmissivity $T$, the effective rain $Q$, the soil density $\rho_{s}$, the cohesion $c$ and the soil friction angle $\varphi$ do appear.

The potential debris flow volumes, for different pluviometric conditions, can be estimated by the evaluation of unstable areas and available sediment layers. Comparing them with the inflow volumes obtained from rainfall-runoff transformation at upper watershed, the average sediment concentration and, consequently, the flow properties can be estimated. 
The inflow hydrograph can then be bulked with sediment for flood routing over the alluvial fan using the FLO-2D software [7]. It can simulate twodimensional flow, hyperconcentrated flow, sediment transport, debris and mud flow; it is based on volume conservation and floodwave attenuation and the numerical modeling of debris flow is represented by a quadratic model:

$$
S_{f}=\frac{\tau_{y}}{\gamma_{m} h}+\frac{K \eta V}{8 \gamma_{m} h^{2}}+\frac{n_{t d}^{2} V^{2}}{h^{4 / 3}}
$$

where $S_{f}$ is the total friction slope, $K$ is the laminar stress of the flow, $n_{t d}^{2}$ is the flow resistance of turbulent and dispersive shear stress, $\tau_{m}$ is the specific weight of the mixture, $V$ is the depth-average velocity, $h$ is the height of the mixture, $\eta$ and $\tau_{y}$ are the rheologic parameters which represent the viscosity and the yield stress. The model application can give detailed outputs on depth and velocity of debris flow in the stream and over the alluvial fan.

\subsection{Debris flow risk assessment}

Risk is the probability of harmful consequences, or expected losses (deaths, injuries, property, livelihoods, economic activity disrupted or environment damaged) resulting from interactions between natural or human-induced hazards and vulnerable conditions ISDR Secretariat [8].

Conventionally, risk is expressed by the notation:

$$
\text { Risk }=\text { Hazard } x \text { Vulnerability } x \text { Exposure }
$$

Hazard is a potentially damaging physical event, phenomenon or human activity. It is related to the probability and generally assessed in terms of "frequency intensity- location" related to the specific event occurrence.

The methodology used in this work to delineate debris flow hazard was first applied in northern Venezuela Garcia et al. [9]. It is based on Swiss and Austrian standards OFEE et al. [10], Fiebiger [11], in which three zones of different hazard level are defined. Debris flow hazard is a function of frequency and intensity: large events occur less frequently but have high intensity expressed in terms of flow depth and velocity; smaller events are more frequent but less damaging. In this study, the probability regions are defined for return periods of 50, 200 and 500 years, tab. 2. Frequency and location are represented by inundation maps of assigned return periods and intensity is a function of flow depth $h$ and velocity $v$. To define the event intensity the Swiss method modified as in [9] is adopted, tab. 3. It defines the intensity combining $h$ with the product of $h$ by $v$. This enables high intensities to be related to high depths independently of flow velocity.

Vulnerability is the condition determined by physical, social, economic, and environmental factors or processes, which increases the susceptibility of a community to the impact of hazards. Exposure or value of the set of human lives, properties and services represents the real damage to humans, socio-economic assets, staff, settlements and ecosystem functioning Trisorio Liuzzi et al. [12]. The damage assessment is complicated by the problem of assuming a specific 
monetary value, especially for human loss and ecological consequences, and the difficulty of assessing the physical, social and economic capacity of people to react upon the disaster occurrence. A simplified method able to quantify the intrinsic susceptibility of the land-water system is obtained by dividing the elements into homogeneous classes based on the exposure or economic and social value as reported in table 4 .

Table 2: $\quad$ Classes of probability.

\begin{tabular}{cc}
\hline \multicolumn{2}{c}{ PROBABILITY $\boldsymbol{P}$} \\
\hline $20<\mathbf{T}_{\mathbf{r}} \leq 50$ & High \\
\hline $100<\mathbf{T}_{\mathbf{r}} \leq 200$ & Medium \\
\hline $300<\mathbf{T}_{\mathbf{r}} \leq 500$ & Low \\
\hline
\end{tabular}

Table 3: Event intensities for debris flow and definition of hazard potential.

\begin{tabular}{|c|c|c|}
\hline \multicolumn{3}{|l|}{ INTENSITY $I$} \\
\hline $\mathrm{vxh}>1 \mathrm{~m}^{2} / \mathrm{s}$ & & High \\
\hline $0.2 \mathrm{~m} / \mathrm{s}<\mathrm{vxh} \leq 1 \mathrm{~m}^{2} / \mathrm{s}$ & & Medium \\
\hline $0.2 \mathrm{~m}<\mathrm{h} \leq 1 \mathrm{~m}$ & & Low \\
\hline $\begin{array}{c}\text { HAZARD } \\
(P \times I) \\
\end{array}$ & & $\begin{array}{l}\text { Map } \\
\text { color }\end{array}$ \\
\hline $\begin{array}{l}\text { Persons are in danger both inside and outside their } \\
\text { houses. Buildings can be destroyed. }\end{array}$ & High & \\
\hline $\begin{array}{l}\text { Persons are in danger outside their houses. } \\
\text { Buildings may suffer damage and possible destruction } \\
\text { depending on construction materials. }\end{array}$ & Medium & \\
\hline $\begin{array}{l}\text { Danger to persons is low or non-existent. } \\
\text { Buildings may suffer little damage, but flooding or } \\
\text { sedimentation may affect building interiors. }\end{array}$ & Low & \\
\hline
\end{tabular}

Table 4: $\quad$ Classes of susceptibility.

\begin{tabular}{lcc}
\hline \multicolumn{1}{c}{ SUSCEPTIBILTY } & Map color \\
\hline $\begin{array}{l}\text { Continuous and discontinuous built-up } \\
\text { areas, venues of public Authorities, } \\
\text { hospitals, schools, barracks, power stations, } \\
\text { etc. }\end{array}$ & Special buildings & $\begin{array}{l}\text { Very } \\
\text { high }\end{array}$ \\
\hline $\begin{array}{l}\text { Factories, industries, laboratories, airports, } \\
\text { private houses, railways stations, parking, } \\
\text { strategic municipal road, provincial and } \\
\text { state roads, dams, bridges and long distance } \\
\text { power lines, residential areas, hotels, } \\
\text { trading centers, etc. }\end{array}$ & Industries, \\
\hline $\begin{array}{l}\text { Water treatment systems, quarries and } \\
\text { landfills, municipal roads, railways lines, } \\
\text { aqueducts, green belts, etc. }\end{array}$ & \\
\hline $\begin{array}{l}\text { Olive groves, vineyards and fruit orchards, } \\
\text { sown lands, vegetables, nursery-gardening } \\
\text { and green-house crops, specialized and } \\
\text { mixed crops, farms, etc. }\end{array}$ & Special crops \\
\hline
\end{tabular}


Natural waters, unprotected or uninhabited areas, broad-leaf and riparian woods and rangeland are areas of zero susceptibility.

The risk area classification is produced by combining hazard and susceptibility maps. The product is a debris flow risk map in which very high (R4), high (R3), moderate (R2) and low risk (R1) areas are identified, fig. 5.

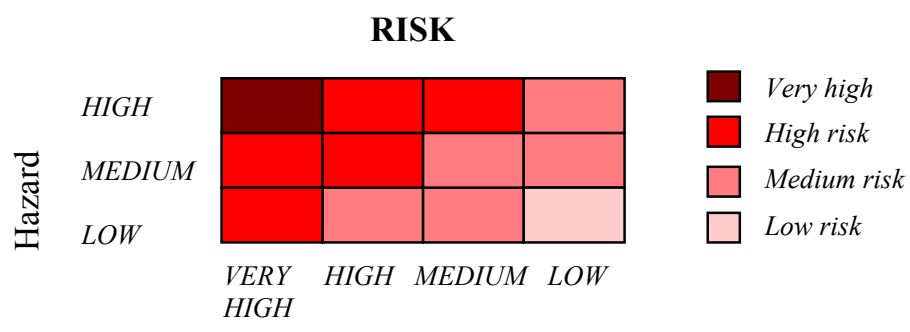

Susceptibility

Figure 5: Risk classification.

\section{Results}

The stability model SHALSTAB was applied to the upper watershed to calibrate the volumetric concentration of the events having return periods of 50, 200 and 500 years. The high instability areas were differentiated from the low instability ones and the potential instability map was determined.

In order to obtain a complete spatial distribution of the different geological units in the basin, the geolithological features of the area were defined and the sediment source areas were located (aerial photos technique). To characterize the geo-mechanical behaviour of the soil some field surveys and laboratory tests were carried out Bisantino et al. [13]. Table 5 reports the main physical and mechanical properties of the soil.

Table 5: $\quad$ Physical and mechanical properties of the soil.

\begin{tabular}{lrl}
\hline Cohesion $c$ & 2500 & $\mathrm{~N} / \mathrm{m}^{2}$ \\
\hline Angle of internal friction $\phi$ & 31 & $\circ$ \\
\hline Saturated hydraulic conductivity $K_{\text {sat }}$ & $10^{-6}$ & $\mathrm{~m} / \mathrm{s}$ \\
\hline Saturated specific weigth $\gamma_{\text {sat }}$ & 1600 & $\mathrm{~kg} / \mathrm{m}^{3}$ \\
\hline
\end{tabular}

From the field survey and photo interpretation, the thickness of deposits present in the watershed and prone to landsliding was evaluated. Such thickness, represented by a $10 \times 10 \mathrm{~m}$ grid, was combined with the stability model to get the potentially unstable volumes. These results were compared with those derived from the main empirical formulas available in the literature Bisantino et al. [14].

The inflow hydrographs at the fan apex were derived from the rainfall-runoff transformation obtained applying the kinematic rational method for different 
return periods and using historical rain records and the July 1972 event data. From inflow and debris volume the average volumetric concentrations of the three events were calculated and a variable distribution was assigned as shown in figure 6 .

To simulate debris flow hazard on the alluvial fan the FLO-2D model was applied using a grid system of 3319 elements $(50 \mathrm{~m} \times 50 \mathrm{~m})$ and elevation points from a DTM $(5 \mathrm{~m}$ x $5 \mathrm{~m})$ digital map. Debris flow rheology and hydraulic parameters were kept at constant values and estimated from the literature. From FLO-2D application with the three return periods, the maximum velocities and depths were derived and the intensity maps based on the established criteria were calculated. The model determines hazard potential maps by combining intensity and event return periods.

The susceptibility map was derived from the land use map relative to valley areas. Each element was assigned to the corresponding class. From the performed analysis, two areas can be defined: an upstream area where susceptibility varies from low to medium, due to the extent of natural and agricultural areas and a downstream area where the susceptibility of elements considerably increases because of the presence of the Manfredonia town and industrial activities.

The risk map was obtained by combining the susceptibility and hazard maps. Introducing hydraulic management works in the system new risk conditions were defined for the alluvial fan, figure 8 . For this purpose, the representative profile of the Pulsano torrent was used as input variable and then modified by several configurations of check dams. The influence of these works on runout distances, flow depths and velocities was quantified.

\section{Conclusions}

Debris flows are among the major problems of hydrogeological instability in south-Gargano torrential basins. They originate from weathering of the calcareous rocks that constitute the geological parent material. The interpretation of such a phenomena is complex due to the absence of monitoring and, often, to the long time interval since the most intense events, which makes the definition of debris flow triggering conditions and routing difficult. In the case of Pulsano torrent, an integrated approach was applied. It was based on the application of SHALSTAB stability model for determining debris flow triggering conditions and on the two-dimensional FLO-2D model for simulating its routing. The flooded areas so obtained were quite consistent with those reconstructed on the basis of the scarce existing documentation and of the performed field surveys. The debris flow characteristics (flow depths and velocity) derived through the modeling allows obtaining a hazard map and then a risk map once the susceptibility map of the area is made. Using this approach a double purpose can be achieved: an approximately good determination of the real risk conditions of valley areas and a more effectively definition of the type, size and location of the management works with a view to reduce the risk conditions. 

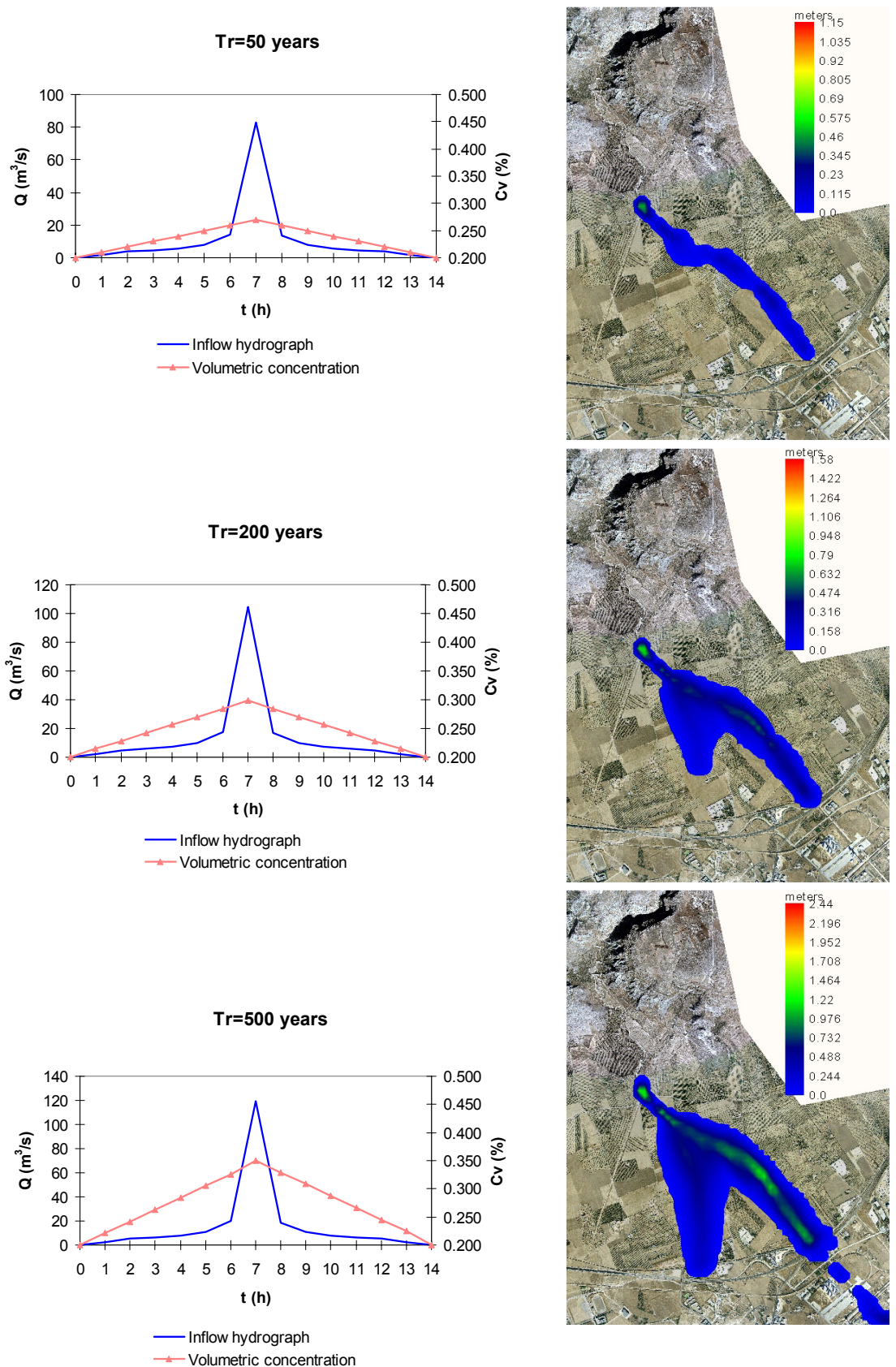

Figure 6: Inflow hydrographs and sediment concentration distributions (left) and maximum flow depth maps (right) for 50, 200 and 500 years return periods. 

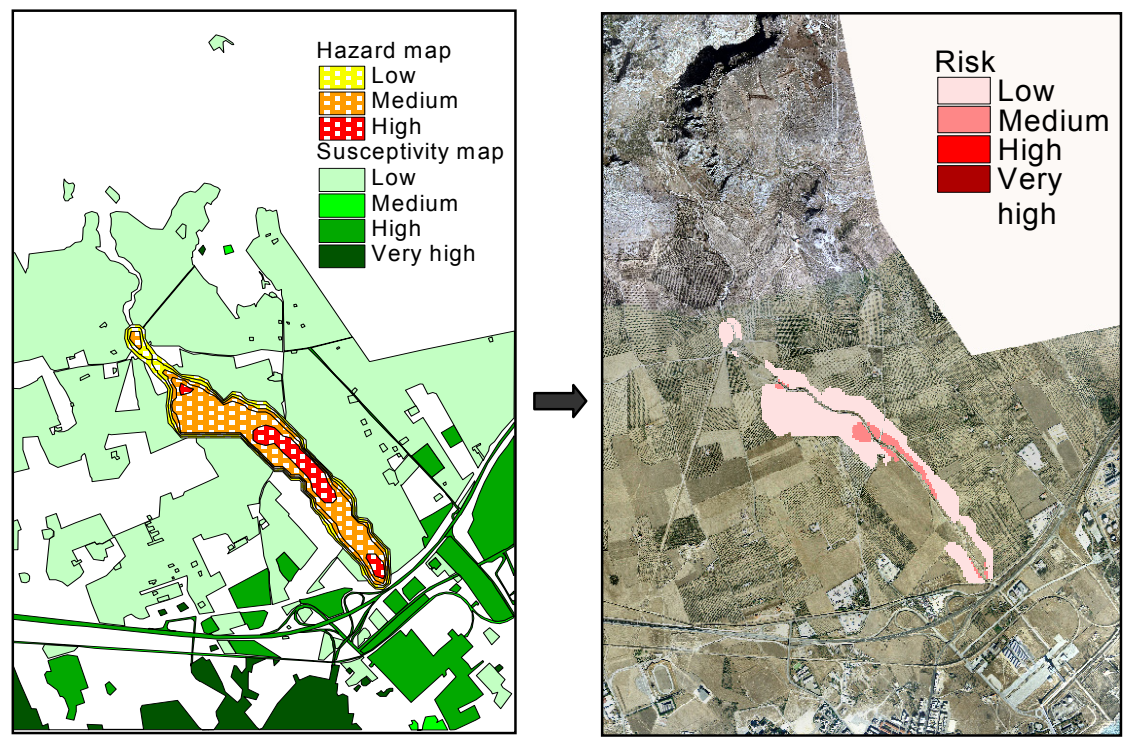

Figure 7: Risk map for the Pulsano watershed.

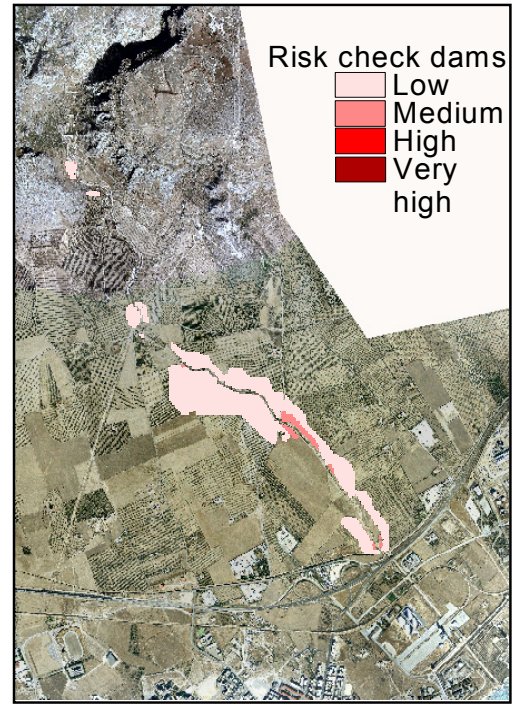

Figure 8: Risk map in presence of two check dams at the fan apex.

\section{References}

[1] Curci, D., Gentile, F., \& Puglisi, S., Sulla difesa idraulica della città di Manfredonia. Atti del Convegno AIIA: Ingegneria Agraria per lo sviluppo dei paesi del Mediterraneo. Vieste (Italy), 2001. 
[2] Montgomery, D. R. \& Dietrich, W. E., A phisically based model for topographic control on shallow landsliding. Water Resources Research, 30(4), pp. 1153-1171, 1994.

[3] Pack, R.T., Tarboton, D.G. \& Goodwin, C.N., GIS-based landslide susceptibility mapping with SINMAP. Proc. of the 34th Symposium on Engineering Geology and Geotechnical Engineering, Bay, J.A. (editor), 34, pp.219-231, 1999.

[4] Hammond, C., Hall, D., Miller, S. \& Swetik, P., Level I stability analysis (LISA) Documentation for Version 2, General Technical Report INT-285, USDA Forest Service Intermountain Research Station, 1992.

[5] Iverson, R.M., Landslide triggering by rain infiltration. Water Resources Research 36(7), pp. 1897-1910, 2000.

[6] Morrissey, M. M., Wieczorek, G. F. \& Morgan B. A., A Comparative Analysis of Hazard Models for Predicting Debris Flows in Madison County, Virginia. USGS publication, 2001. http://pubs.usgs.gov/

[7] FLO-2D Software, Inc. 2004. FLO-2D User's Manual.

[8] ISDR- International Strategy for Disaster Reduction, International Decade for Natural Disaster Reduction: successor arrangements. Report of the Secretary-General, 1999. www.unisdr.org/

[9] Garcia, R., Lopez, J.L., Noya, M., Bello, M.E., Bello, M.T., Gonzáles, N., Peredes, G., Vivas, M.I. \& O’Brien, J.S., Hazard mapping for debris-flow events in the alluvial fans of northern Venezuela. Proc. of the 3rd International Conference on debris-flow hazards mitigation: mechanism, prediction and assessment. Davos, Switzerland, Millpress, pp. 589-599, 2003.

[10] OFEE, OFAT \& ODEFP (Switzerland). Prise en compte des dangers dus aux crues dans le cadre des activités de l'aménagement du territoire. Bienne, 1997.

[11] Fiebiger, G., Zonage des risques naturels en Autriche. Journal of Torrent, Avalanche, Landslide and Rockfall Engineering, 61(134), pp. 155-163, 1997.

[12] Trisorio Liuzzi G., Gentile F. \& Bisantino T., Water-Land related disasters: the participatory approach as integral part of the risk management". Workshop proceedings: Promoting participatory management of the land system to enhance soil conservation. Medcoastland Project - Alexandria (Egypt), pp. 347-361, 2004.

[13] Bisantino T., Gentile F. \& Puglisi S., Analisi integrata dei fenomeni di colata detritica nei bacini torrentizi sud-garganici (Italia meridionale). Atti del $10^{\circ}$ Congresso Interpraevent, band 1 pp. 15-26, Riva del Garda (Italy), 2004.

[14] Bisantino T., Gentile F. \& Trisorio-Liuzzi G., Valutazione del potenziale detritico in un bacino torrentizio dell'Italia meridionale. Atti dell' VIII Convegno Nazionale AIIA, Catania (Italy), 2005. 